\title{
Lysozyme Degradation by the Bovine Multicatalytic Proteinase Complex (Proteasome): Evidence for a Nonprocessive Mode of Degradation ${ }^{\dagger}$
}

\author{
Rong Wang, ${ }^{\ddagger}$ Brian T. Chait,,${ }^{\ddagger}$ Imrey Wolf, ${ }^{\S}$ Ronald A. Kohanski, ${ }^{\S}$ and Christopher Cardozo*,ll \\ Departments of Medicine, Pharmacology, and Biochemistry of The Mount Sinai School of Medicine, \\ New York, New York 10029, and Laboratory for Mass Spectrometry and Gaseous Ion Chemistry, Rockefeller University,
} New York, New York 10021

Received April 9, 1999; Revised Manuscript Received July 23, 1999

\begin{abstract}
The multicatalytic proteinase complex (MPC, proteasome) is composed of 28 subunits organized into four rings surrounding a water-filled canal. The catalytic centers face the inner canal confining protein substrates to an enclosed space. Experimental findings obtained with MPC from archaebacteria suggest that degradation of proteins by the complex is processive and have led to the proposal that the lengths of the peptides formed during degradation depend on the distances between active sites in the catalytic chamber. To test whether these postulates are valid for the MPC from a higher organism, we examined the size distributions of products formed early versus late in the course of protein degradation using reduced carboxamidomethylated lysozyme (RCM-lysozyme) and MPC from bovine spleen and pituitary. The majority of final degradation products ranged in length from 6 to 20 amino acids without a clear predilection for peptides of a particular, uniform size. Our observations suggest that selection of cleavage sites is governed by the amino acid sequence specificity of the MPC catalytic sites rather than the distances between the active sites. Early in the course of degradation, peptides with masses between 5 and $10 \mathrm{kDa}$ accumulated in more than 80-fold molar excess over the MPC, indicating dissociation of large, partially degraded intermediates. Initial cleavages occurred at distances between 10 and 44 amino acids from the $\mathrm{N}$ - or C-terminus of the molecule and often involved removal of a fragment from both the $\mathrm{N}$ - and $\mathrm{C}$-termini of RCM-lysozyme. Our data indicate that degradation of proteins by MPCs from higher organisms involves a nonprocessive mechanism comprised of multiple, independent cleavages with dissociation of degradation intermediates. A general model for protein degradation by the MPC is discussed.
\end{abstract}

The multicatalytic proteinase complex (MPC, ${ }^{1}$ proteasome) is a high molecular mass, intracellular particle essential for the survival of eukaryotic cells $(1-5)$. It is involved in both ubiquitin-dependent and ubiquitin-independent degradation of cytosolic, nuclear, and membrane-bound proteins. As the proteolytic core of the ubiquitin-dependent pathway, the MPC is implicated in cell cycle progression, signal transduction, regulation of levels of protooncogene products, and destruction of damaged or improperly folded proteins $(1-$ 5 ). The MPC is a major factor in processing peptide antigens for presentation on major histocompatibility complex (MHC) class I molecules $(6,7)$.

A bacterial ancestor of the MPC has been identified in the archaebacterium Thermoplasma acidophilum (8). This

\footnotetext{
† Supported by NIH Grants DK25377, DK50074, and RR00862.

* Address correspondence to this author at Box 1215, The Mount Sinai School of Medicine, 1 Gustave L. Levy Place, New York, NY 10029. Tel (212) 659-1714; Fax (212) 831-0114; Email c_cardozo@ smtplink.mssm.edu.

$\div$ The Rockefeller University.

$\S$ Department of Biochemistry, The Mount Sinai School of Medicine.

"Departments of Medicine and Pharmacology, The Mount Sinai School of Medicine.

${ }^{1}$ Abbreviations: Amino acids are designated by their conventional one- or three-letter codes. HPLC, high-pressure liquid chromatography; MALDI-TOF-MS, matrix-assisted laser desorption/ionization time-offlight mass spectrometry; MHC, major histocompatibility complex; MPC, multicatalytic proteinase complex; RCM-lysozyme, $S$-carboxamidomethylated lysozyme; TFA, trifluoroacetic acid.
}

more primitive MPC is assembled from 28 subunits of two distinct types, designated $\alpha$ and $\beta$. The MPC from eukaryotes is also assembled from 28 polypeptides (3) but of 14 types, which can be classified as $7 \alpha$ and $7 \beta$ subunits on the basis of similarities in amino acid sequence to subunits of the archaebacterial enzyme. Exposure of cells to interferon $\gamma$ induces the expression of LMP2, LMP7, and LMP10, which replace three constitutively expressed $\beta$-type subunits: $\mathrm{X}$, $\mathrm{Y}$, and $\mathrm{Z}(9-11)$. This alters the cleavage specificity of the MPC (12-16) and facilitates generation of antigenic peptides $(17-20)$.

Electron microscopic and crystallographic studies indicate that the subunits are assembled into a cylindrical particle with a water-filled tunnel $(8,21-23)$. Active sites are located on $\beta$-type subunits and face the central cavity $(8,23-27)$, which is often referred to as a catalytic chamber. Thus, protein substrates become accessible to active sites only after passing through pores at the entrance to the central canal. These pores may be located either at the ends of the particle $(8,28,29)$ or at specific locations along its sides $(23)$. It is believed that the pore diameter is on the order of 1-2 nm $(8,23,28,29)$, a finding that agrees well with observations that only extensively unfolded proteins are susceptible to degradation $(29,30)$. The organization of the MPC thus protects normally folded proteins from degradation.

These structural features have been suggested to promote an "all or none" mode of degradation in which the end of a 
protein enters the catalytic chamber through a pore and is degraded in a series of linked reactions in which small fragments are removed processively from the end of the protein. This pattern of degradation was supported by kinetic studies of protein degradation by the MPC isolated from archaebacteria and by the analysis of the kinetics of the degradation of insulin B-chain $(31,32)$. However, conflicting findings came from studies of the degradation of synthetic fragments of ovalbumin, which revealed the formation of intermediates of degradation (33) that were not compatible with a processive mechanism. Whether intermediates are formed during the normal course of degradation of proteins by the MPC is not known. However, experiments in the presence of low concentrations of the denaturing detergent SDS demonstrated the accumulation of large intermediates during degradation of lysozyme (34), and studies of the degradation of casein by $\mathrm{N}$-acetylimidazole-treated MPC found accumulation of degradation intermediates that could be further degraded by the untreated MPC (35). These findings indicate that intermediates can be formed by the MPC and can dissociate from it. Moreover, whereas the highly ordered processive mechanism of protein degradation might be predicted to require energy for trapping of the protein substrate and movement of the polypeptide into the catalytic chamber in a defined manner, studies of the amino acid sequences of MPC subunits reveal no features of known ATPases (3). Furthermore, the overall proteolytic activity of the MPC is either unaffected or only modestly stimulated by ATP $(30,36-39)$. These findings argue against the presence in the MPC of an energy-dependent mechanism for trapping and moving a protein substrate in a defined manner during the degradation process.

Structural factors may also constrain the size of the final products of degradation. Crystallographic analysis of the MPC from archaebacteria showed that the shortest distance between two active sites was $28 \AA(8)$, or approximately the distance spanned by $7-8$ amino acids. Fragments of this size resulted from degradation of insulin B-chain by this primordial MPC and favored the proposal that distance between active sites provides a molecular ruler governing the sizes of products (40). Possible functional implications of these findings stem from observations that peptides bound to MHC class I molecules have a similar size range. However, studies with more complex proteins as substrates found no such size predilection (41). The possible existence of a molecular ruler for cleavages in proteins by eukaryotic MPCs has not been investigated. Neither it is known whether incorporation of the LMP subunits, which facilitate antigen presentation $(17-20)$, shifts the size predilection of such a molecular ruler toward peptides of $8-9$ amino acids, the size of most MHC class I-restricted antigenic peptides.

To gain insight into the pattern of protein degradation by the mammalian 20S MPC, we investigated the degradation of reduced and S-carboxamidomethylated lysozyme (RCMlysozyme) using two forms of eukaryotic MPCs, one purified from bovine pituitary, the other from bovine spleen. Denatured lysozyme was used because prior studies have shown that denaturation greatly favors access of the protein to the catalytic chamber $(29,30,42)$. Previous experiments showed that the pituitary MPC contains the $\mathrm{X}, \mathrm{Y}$, and $\mathrm{Z}$ subunits and virtually none of the LMP subunits, whereas in the spleen MPC the $\mathrm{X}, \mathrm{Y}$, and $\mathrm{Z}$ subunits are nearly completely replaced by the LMP2, LMP7, and LMP10 subunits (15). The effect of this replacement was studied by analyzing and comparing the size distributions of final products generated by each of the MPCs. The mechanisms of protein degradation were assessed by following the appearance of degradation products over time and by identification of fragments via mass spectrometry. In these studies, we found evidence of a nonprocessive mode of protein degradation and observed that the final products of degradation included peptides with a broad size distribution, which was similar for the two MPCs.

\section{MATERIALS AND METHODS}

\section{Materials}

The MPC was isolated from bovine pituitaries or spleen as an apparently homogeneous preparation essentially as described (15). Aliquots of the enzyme were stored at -70 ${ }^{\circ} \mathrm{C}$. S-Carboxamidomethylated lysozyme (RCM-lysozyme) was prepared as described (43). All other reagents were of the highest quality available and were obtained from Sigma Chemical Co. (St. Louis, MO) or from Fisher Scientific (Pittsburgh, PA).

\section{Methods}

Gel Permeation Chromatography of Degradation Products. Reactions containing an $0.5 \mathrm{~mL}$ aliquot of RCMlysozyme solution $(0.135 \mathrm{mg} / \mathrm{mL}$ in $50 \mathrm{mM}$ Tris-acetate, $\mathrm{pH} 8.0)$ and $5 \mu \mathrm{L}$ of MPC solution $(1 \mu \mathrm{g} / \mu \mathrm{L})$ were carried out at $37{ }^{\circ} \mathrm{C}$ and were stopped by adding $2 \mu \mathrm{L}$ of $85 \%$ phosphoric acid after the desired times. Of the reaction mixture $(100 \mu \mathrm{L})$ was applied to a $0.9 \times 27 \mathrm{~cm}$ column of Bio-Gel P10 (Bio-Rad, Hercules, CA) equilibrated with $0.12 \%$ TFA, $1 \%$ methanol, and $20 \%$ acetonitrile in water and eluted at $0.1 \mathrm{~mL} / \mathrm{min}$ with this buffer. Eluting peptides were detected by absorbance at $278 \mathrm{~nm}$. Molecular weights of peptides were estimated from a standard curve generated from lysozyme $(14.5 \mathrm{kDa})$, aprotinin $(6.5 \mathrm{kDa})$, and purified lysozyme fragments of known molecular masses of $3150 \mathrm{Da}$ (fragment from V8 protease digest), $2880 \mathrm{Da}$ (fragment from cyanogen bromide digest), and $2100 \mathrm{Da}$ (synthetic peptide).

HPLC Analysis of the Time Course of Formation and Degradation of Reaction Intermediates. Reactions containing $10 \mu \mathrm{g}$ of MPC and $1 \mathrm{~mL}$ of RCM-lysozyme solution (0.17 $\mathrm{mg} / \mathrm{mL}$ in $50 \mathrm{mM}$ Tris-acetate, $\mathrm{pH} 8.0$ ) were started by adding MPC to a prewarmed RCM-lysozyme solution. Reactions were incubated at $37{ }^{\circ} \mathrm{C}$ for various times and were stopped by the addition of $10 \mu \mathrm{L}$ of phosphoric acid $(85 \% \mathrm{w} / \mathrm{w})$. The reaction mixture $(150 \mu \mathrm{L})$ was subjected to HPLC analysis on a Deltapak C18 column $(2 \times 150 \mathrm{~mm}$, Waters) equilibrated with $98 \%$ solvent A and $2 \%$ solvent B, where solvent A was $0.12 \%$ TFA in water and solvent B was $0.1 \%$ TFA in acetonitrile. Peptides were eluted with a linear gradient from $2 \%$ to $45 \%$ solvent B over $60 \mathrm{~min}$ at a flow rate of $0.4 \mathrm{~mL} / \mathrm{min}$. The column was then washed with a linear gradient over $10 \mathrm{~min}$ from 45 to $80 \%$ solvent B. Eluting peptides were detected by absorbance at $220 \mathrm{~nm}$. Integration of peaks was achieved by analysis of digitized images (Arcus II scanner) of the chromatograms using the Measure Black and White Pixels macro of NIH Image (version 1.60).

Mass Spectrometry Analysis. For analysis of degradation intermediates, incubations of MPC with RCM-lysozyme were 


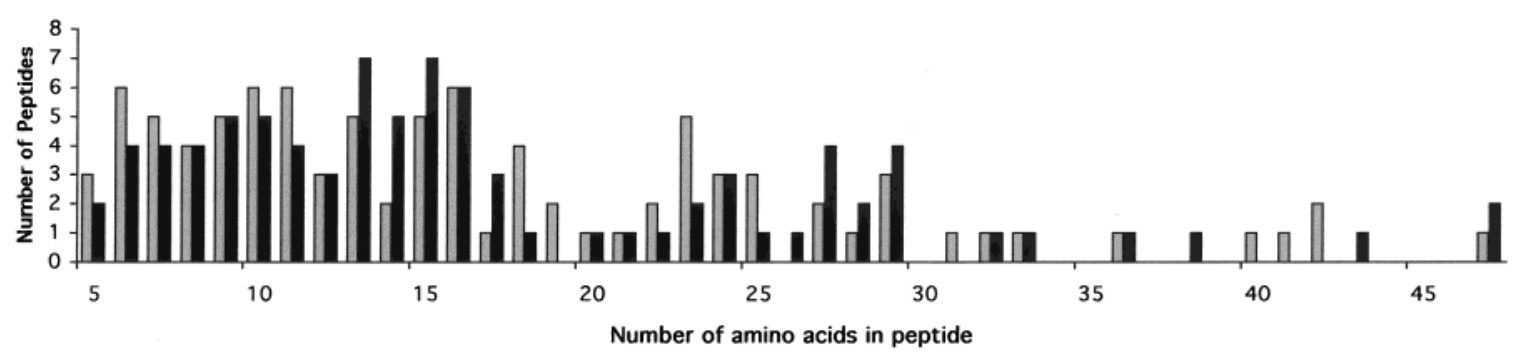

FIGURE 1: Size distribution of final degradation products formed from RCM-lysozyme after $24 \mathrm{~h}$ incubation with the MPC from bovine pituitary (gray bars) or bovine spleen (black bars) MPCs. Masses and predicted lengths of peptides in reaction mixtures were determined by MALDI-TOF-MS as described under Materials and Methods.

carried out for $10 \mathrm{~min}$ as above at a concentration of RCMlysozyme of $0.38 \mathrm{mg} / \mathrm{mL}$. The reaction mixture $(150 \mu \mathrm{L})$ was subjected to HPLC on a Deltapak C18 column $(3.9 \times$ $150 \mathrm{~mm}, 300 \AA$, $5 \mu \mathrm{m}$, Waters) equilibrated with $90 \%$ solvent $\mathrm{A}$ and $10 \%$ solvent $\mathrm{B}$, where solvent $\mathrm{A}$ was $0.1 \%$ trifluoroacetic acid in water and solvent B was $0.08 \%$ trifluoroacetic acid in acetonitrile. Peptides were eluted with a linear gradient from $10 \%$ to $40 \%$ solvent B over $60 \mathrm{~min}$ at $0.8 \mathrm{~mL} / \mathrm{min}$. Eluting peptides were detected by absorbance at $280 \mathrm{~nm}$ and were collected using an automated fraction collector (1.6 mL fractions). Molecular masses of RCMlysozyme degradation fragments in these fractions, and in the total digest, were measured by matrix-assisted laser desorption/ionization time-of-flight mass spectrometry (MALDITOF-MS) (44). The above HPLC fractions were dried by a speed-vacuum concentrator and redissolved in $20 \mu \mathrm{L}$ of $0.1 \%$ TFA in water/acetonitrile $(1: 1 \mathrm{v} / \mathrm{v})$. One micoliter of the redissolved HPLC fraction solution or crude reaction mixture was mixed with $5 \mu \mathrm{L}$ of a saturated solution of MALDI matrix ( $\alpha$-cyano-4-hydroxycinnamic acid) in formic acid/ water/2-propanol $(1: 3: 3 \mathrm{v} / \mathrm{v} / \mathrm{v})$. A $1.0 \mu \mathrm{L}$ aliquot of the mixed solutions was deposited onto a sample probe and allowed to dry at ambient temperature. MALDI-MS spectra were collected on a linear TOF mass spectrometer equipped with a Nd-YAG laser generating $355 \mathrm{~nm}$ wavelength laser pulses (44). The mass spectra were averages of 200 laser shots and were calibrated with cytochrome $c$. The measured molecular masses from the resulting spectra were searched against the amino acid sequence of RCM-lysozyme for potential matching peptides by using the protein analysis program PAWS (Proteometrics, New York). The identification of fragments was made by searching all potential fragmentation products with the measured molecular masses. This process frequently yields multiple potential fragments that match the measured mass of a given fragment to within the error of the measurement ( $\pm 500 \mathrm{ppm}$ ). Thus, we (a) selected sequences whose calculated masses most closely matched the measured fragment masses and (b) chose sequences for which we observed complementary peptide fragments. For determination of the size distribution of degradation fragments formed after $24 \mathrm{~h}$, reaction mixtures (prepared as above and incubated for $24 \mathrm{~h}$ ) were subjected to MALDI-TOF analysis. The $\alpha$-cyano-4-hydroxycinnamic acid-saturated solution in TFA/water/acetonitrile $(0.1: 50: 50 \mathrm{v} / \mathrm{v} / \mathrm{v})$ was used as matrix as described above. The measured masses of peaks observed in the resulting spectra were used to identify the corresponding peptides and, thereafter, the lengths of these peptides were calculated.

\section{RESULTS}

Distribution of Sizes of Final Products. To compare the size distribution of the final peptide products formed during proteolysis of RCM-lysozyme by the two MPCs, reactions were continued for $24 \mathrm{~h}$ and the molecular masses of the resulting peptide fragments were analyzed by mass spectrometry. On the basis of the amino acid sequence of RCMlysozyme and the observed molecular masses of the peptide fragments, the peptide lengths were calculated and size distributions of the corresponding peptide fragments were obtained (Figure 1). Peptide ions with $\mathrm{m} / \mathrm{z}$ values $<500$ were precluded from this analysis because of the high background of low mass ions arising from matrix molecules. The overall size distributions were similar for the pituitary and spleen MPCs. The majority of peptides ( $>70 \%$ of all peptide fragments observed) were observed to be clustered between 6 and 18 amino acids, although several longer peptides (1847 amino acids) also persisted (30\% of all peptide fragments observed). While a large proportion of peptides were smaller than 18 amino acids, no strong predilection for formation of peptides of a particular size was noted.

Degradation of RCM-Lysozyme Involves Formation of Intermediates. Insights into the mechanism of degradation of proteins can be obtained by following the formation of products of degradation over time. Therefore, the time course of appearance of degradation fragments was followed by HPLC (Figure 2). During degradation of RCM-lysozyme by either pituitary or spleen MPCs, several peaks with relatively long retention times (peak cluster 2 in Figure 2A,C) were observed in chromatograms of reactions from the early time point $(10 \mathrm{~min})$. After longer incubation times $(60 \mathrm{~min}$, Figure 2B,D), these peaks diminished in size or disappeared and were replaced by increased amounts of peptide peaks that eluted with shorter retention times. This observation is consistent with the conversion of peptides within peak cluster 2 to shorter products, indicating that the peptides within peak cluster 2 correspond to degradation intermediates. While the initial rate of degradation of lysozyme was rapid (up to 50\% degradation within $10 \mathrm{~min}$ ), some lysozyme remained at 60 min, consistent with slowing of the reaction at later times. This reduction in rate may be attributable to several factors. The overall rate of degradation of lysozyme is expected to slow as lysozyme concentration decreases. Also, our findings show that during initial cleavage of lysozyme many large products are formed and subsequently degraded; the large products thus compete with lysozyme for access to MPC active sites in a form of competitive inhibition.

Molecular Weights of Intermediates. Intermediates of degradation would be expected to have comparatively high 

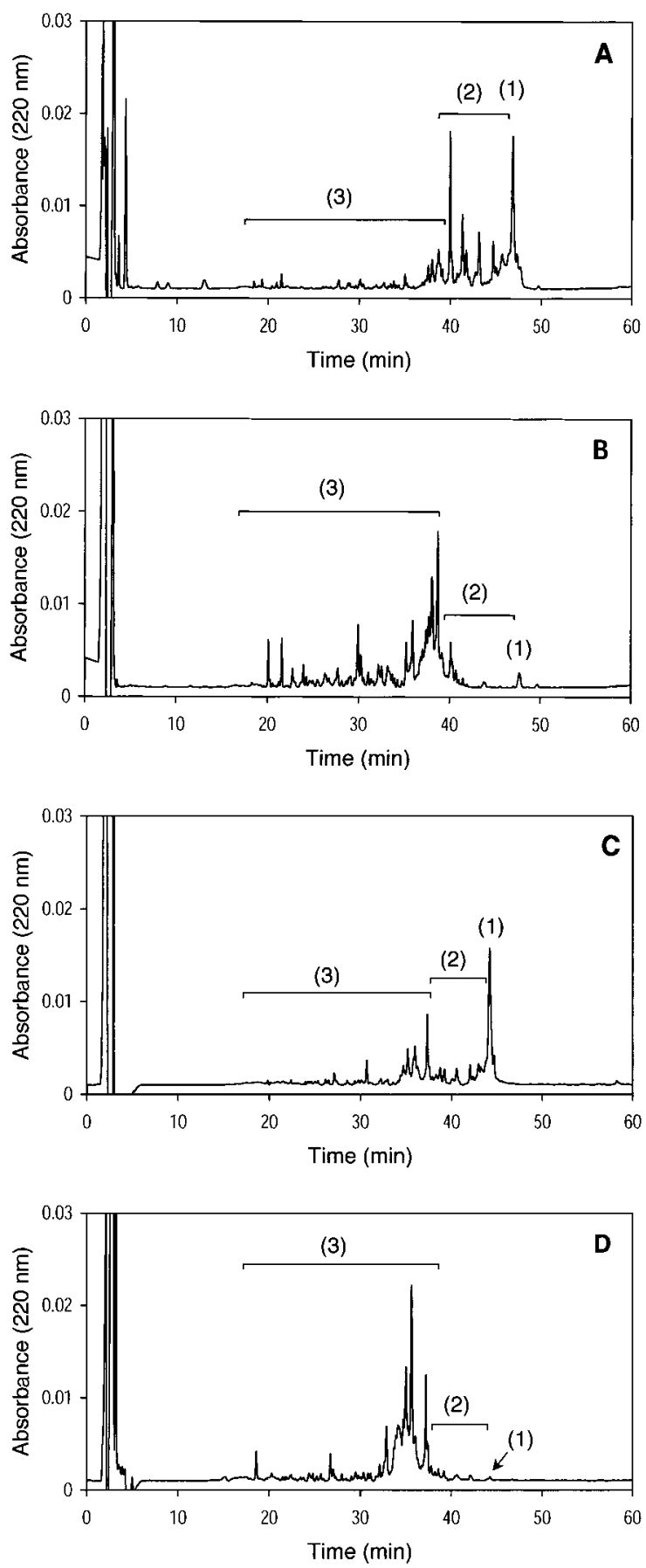

FiguRE 2: Time course of the degradation of RCM-lysozyme. Reactions and separation by HPLC of peptides contained therein were performed as described under Materials and Methods. (A) Incubation for $10 \mathrm{~min}$ with spleen MPC; (B) spleen MPC for 60 min; (C) pituitary MPC for $10 \mathrm{~min}$; (D) pituitary MPC for $60 \mathrm{~min}$. Peak 1 is lysozyme; peaks labeled as 2 and 3 are described in the text.

molecular masses. Hence, reaction mixtures were subjected to gel-permeation chromatography (Figure 3 ) to estimate the molecular weights of the intermediates. The reaction mixture of RCM-lysozyme revealed three partially resolved peaks in the gel-permeation chromatographic analysis after incubation with pituitary MPC for $10 \mathrm{~min}$ (Figure 3A, solid line). Molecular weights of the peptides within these three peaks were calculated by use of a standard curve generated with protein and peptide standards (see Methods). The mean molecular weights are 12000,8200 , and 3200 for peaks I,
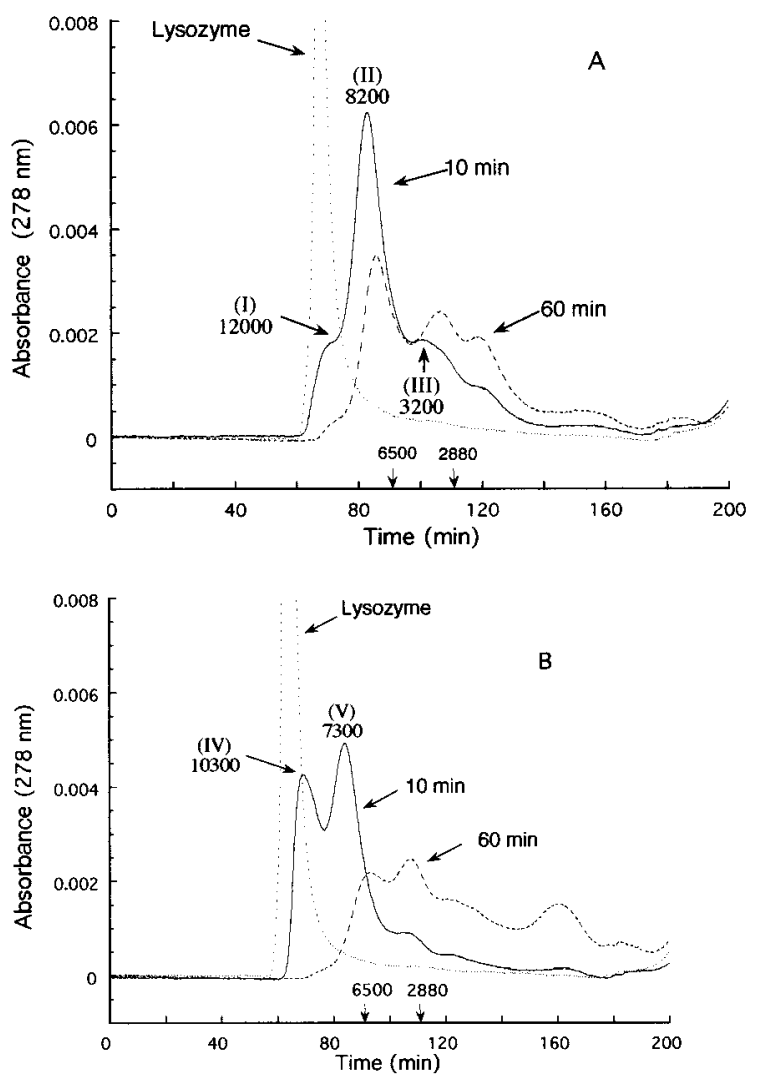

FIGURE 3: Gel-permeation chromatography of degradation products of RCM-lysozyme. Dotted lines represent chromatograms at 0 min incubation; solid lines, those at $10 \mathrm{~min}$; and dashed lines, those after $60 \mathrm{~min}$ of incubation. Retention times of aprotinin (6500 Da) and a $2880 \mathrm{Da}$ fragment of lysozyme are indicated for comparison. (A) Pituitary MPC: the major peaks are labeled I, II, and III; corresponding molecular weights are shown below the label for each peak. (B) Spleen MPC: the major peaks are labeled IV and $\mathrm{V}$; corresponding molecular weights are shown below the label for each peak.

II, and III of Figure 3A, respectively. After longer incubation times a shift in the distribution was observed consistent with conversion of the high molecular weight fragments to smaller products (Figure 3A, dashed line). Similar results were obtained after digestion for 10 min with spleen MPC (Figure 3B, solid line). In this case, two major peaks with mean molecular weights of 10300 and 7300 were observed (peaks IV and V). After longer incubation times, these two peaks were replaced by broad peaks corresponding to peptides having molecular weights $<6500$ (Figure 3B, dashed line).

Identification of Intermediates. To obtain greater insight into the nature of the peptides in peak cluster 2 (Figure 2A,C), we collected fractions eluting from the HPLC column that contained the peptides within these peaks and analyzed the degradation fragments in these samples by mass spectrometry (Table 1). Peptides in the HPLC fractions ranged from 3.5 to $10.2 \mathrm{kDa}$, and were thus significantly larger than the peptides found after $24 \mathrm{~h}$ incubation, which were almost all smaller than 20 amino acids (Figure 1), or approximately $2400 \mathrm{Da}$ (assuming an average of $120 \mathrm{Da}$ per amino acid). Thus, the findings indicate that the peptides found in peak cluster 2 are high molecular weight intermediates. To obtain information about the small peptides removed from the large intermediates we also determined, by mass spectrometry, the molecular masses of all peptides contained in the total 10 min incubation mixture. Unambiguous identification of a 
Table 1: Masses of Peptides in the Late-Eluting Peaks Generated during 10 min of Incubation of RCM-lysozyme with Pituitary or Spleen $\mathrm{MPC}^{a}$

\begin{tabular}{|c|c|c|c|c|c|c|c|c|c|c|c|}
\hline \multirow[b]{2}{*}{ peptide } & \multirow[b]{2}{*}{ mass (Da) } & \multicolumn{2}{|c|}{ HPLC fraction } & \multirow[b]{2}{*}{ corresponding peptide ${ }^{b}$} & \multirow[b]{2}{*}{ error } & \multicolumn{6}{|c|}{ complementary peptide } \\
\hline & & pituitary & spleen & & & $\mathrm{N}$-terminal & mass $(\mathrm{Da})$ & error & C-terminal & mass (Da) & error \\
\hline $1^{c}$ & 10216.0 & 16 & & $\mathrm{R}[14-104] \mathrm{G}$ & 2.9 & & & & & & \\
\hline $2^{d}$ & 9956.9 & & 16 & $\mathrm{~N}[19-107] \mathrm{A}$ & -0.2 & $\mathrm{~K}[1-18] \mathrm{D}$ & 2060.1 & -0.7 & & & \\
\hline $3^{e}$ & 9676.1 & 18 & 18 & $\mathrm{~K}[1-84] \mathrm{L}$ & 0.5 & & & & $\mathrm{~S}[85-129] \mathrm{L}$ & 5110.5 & 0.2 \\
\hline $4^{e}$ & 9373.3 & 17 & 17 & $\mathrm{~L}[8-90] \mathrm{A}$ & 0.9 & & & & $\mathrm{~S}[91-107] \mathrm{A}$ & 1764.9 & 0.0 \\
\hline $5^{d, e}$ & 9279.2 & & 19 & $\mathrm{~A}[10-91] \mathrm{S}$ & -2.2 & $\mathrm{~K}[1-9] \mathrm{A}$ & 1080.1 & 0.9 & $\mathrm{~V}[92-103] \mathrm{N}$ & 1305.1 & -0.6 \\
\hline $6^{d, e}$ & 9271.8 & 15 & & $\mathrm{~F}[38-119] \mathrm{D}$ & -2.8 & $\mathrm{E}[7-37] \mathrm{N}$ & 3530.5 & -0.6 & $\mathrm{~V}[120-129] \mathrm{L}$ & 1259 & -0.6 \\
\hline $7^{e}$ & 9262.9 & 20 & 20 & $\mathrm{~A}[9-90] \mathrm{A}$ & -1.9 & & & & $\mathrm{~S}[91-107] \mathrm{A}$ & 1764.9 & 0.0 \\
\hline $8^{c}$ & 9062.0 & & 20 & $\mathrm{~F}[3-80] \mathrm{C}$ & 2.8 & & & & & & \\
\hline \multirow[t]{2}{*}{$9^{d}$} & 8985.9 & 15 & & $\mathrm{~S}[24-104] \mathrm{G}$ & 0.7 & $\mathrm{~L}[8-23] \mathrm{Y}$ & 1836.4 & -0.3 & & & \\
\hline & & & & & & $\mathrm{K}[1-23] \mathrm{Y}$ & 2713.7 & -0.6 & & & \\
\hline $10^{d}$ & 8907.7 & 20 & & $S[36-114] R$ & 0.9 & $\mathrm{~A}[9-35] \mathrm{E}$ & 3085.6 & 0.9 & & & \\
\hline $11^{d}$ & 8886.1 & & 19 & $\mathrm{Y}[53-129] \mathrm{L}$ & -0.3 & $\mathrm{~K}[33-52] \mathrm{D}$ & 2247.7 & -0.4 & & & \\
\hline \multirow[t]{2}{*}{$12^{e}$} & 8778.0 & 17 & & $\mathrm{~A}[42-119] \mathrm{D}$ & 0.5 & & & & $\mathrm{~V}[120-129] \mathrm{L}$ & 1259 & -0.6 \\
\hline & & & & $\mathrm{G}[22-99] \mathrm{V}$ & -1.5 & $\mathrm{~K}[1-21] \mathrm{R}$ & 2492.8 & 0.1 & & & \\
\hline \multirow[t]{2}{*}{$13^{d}$} & 8749.8 & 16 & 16 & $\mathrm{~S}[36-113] \mathrm{N}$ & 2.6 & $\mathrm{~A}[9-35] \mathrm{E}$ & 3085.6 & 0.9 & & & \\
\hline & & & & $\mathrm{W}[28-105] \mathrm{M}$ & -3.4 & $\mathrm{~K}[1-27] \mathrm{N}$ & 3085.6 & -1.1 & $\mathrm{~N}[106-129] \mathrm{L}$ & 2974.1 & 0.2 \\
\hline \multirow[t]{2}{*}{14} & 8647.2 & 17 & 17 & $\mathrm{~K}[1-75] \mathrm{L}$ & 0.2 & & & & & & \\
\hline & & & & $\mathrm{C}[30-107] \mathrm{A}$ & 0.9 & & & & & & \\
\hline \multirow{4}{*}{15} & 8391.2 & 16 & 16 & $\mathrm{~A}[9-81] \mathrm{S}$ & -2.2 & & & & & & \\
\hline & & & & $\mathrm{A}[10-82] \mathrm{A}$ & -2.2 & & & & & & \\
\hline & & & & $\mathrm{R}[21-94] \mathrm{C}$ & 1.7 & & & & & & \\
\hline & & & & $\mathrm{N}[44-117] \mathrm{G}$ & -1.1 & & & & & & \\
\hline $16^{d}$ & 8252.7 & 15 & & $\mathrm{D}[18-89] \mathrm{T}$ & 1.1 & $\mathrm{C}[6-17] \mathrm{L}$ & 1356.9 & -0.4 & & & \\
\hline \multirow[t]{2}{*}{17} & 8050.4 & 17 & 17 & $\mathrm{~V}[2-71] \mathrm{G}$ & -1.7 & & & & & & \\
\hline & & & & $\mathrm{S}[50-120] \mathrm{V}$ & -2.6 & & & & & & \\
\hline \multirow[t]{3}{*}{$18^{d}$} & 7661.2 & 16 & 16 & $\mathrm{R}[45-112] \mathrm{R}$ & -0.9 & $\mathrm{~A}[31-44] \mathrm{N}$ & 1543.2 & -0.6 & & & \\
\hline & & & & $\mathrm{T}[47-114] \mathrm{R}$ & -0.9 & $\mathrm{~F}[34-46] \mathrm{N}$ & 1543.2 & -0.6 & & & \\
\hline & & & & $\mathrm{Q}[41-109] \mathrm{V}$ & 0.1 & & & & & & \\
\hline \multirow[t]{2}{*}{$19^{d}$} & 7623.7 & & 17 & $\mathrm{~S}[36-104] \mathrm{G}$ & -0.6 & $\mathrm{~V}[2-35] \mathrm{E}$ & 3948.8 & -0.4 & & & \\
\hline & & & & $\mathrm{G}[16-81] \mathrm{S}$ & -0.6 & $\mathrm{~K}[1-15] \mathrm{H}$ & 1774 & 0.1 & & & \\
\hline $20^{c}$ & 6940.2 & 15 & & $\mathrm{~S}[60-120] \mathrm{V}$ & 2.4 & & & & & & \\
\hline $21^{e}$ & 6781.2 & & 16 & $\mathrm{G}[26-84] \mathrm{L}$ & 0.0 & & & & $\mathrm{~S}[85-129] \mathrm{L}$ & 5110.5 & 0.2 \\
\hline $21^{d}$ & & & & $\mathrm{~L}[25-83] \mathrm{L}$ & 0.0 & $\mathrm{~A}[11-24] \mathrm{S}$ & 1668.1 & -0.3 & & & \\
\hline \multirow[t]{2}{*}{22} & 5610.1 & 15 & & $\mathrm{~L}[75-124] \mathrm{I}$ & 0.2 & & & & & & \\
\hline & & & & $\mathrm{Y}[20-67] \mathrm{G}$ & -0.2 & & & & & & \\
\hline $23^{e}$ & 5542.3 & 21 & 20 & $\mathrm{~K}[1-48] \mathrm{D}$ & -1.2 & & & & G[49-101]D & 5931.3 & -0.9 \\
\hline \multirow[t]{2}{*}{$24^{d}$} & 5417.8 & 20 & & $\mathrm{~N}[37-83] \mathrm{L}$ & -0.1 & $\mathrm{Y}[23-36] \mathrm{S}$ & 1631.9 & -0.1 & & & \\
\hline & & & & $\mathrm{F}[38-84] \mathrm{L}$ & -1.0 & $\mathrm{E}[7-37] \mathrm{N}$ & 3530.5 & -0.6 & & & \\
\hline \multirow[t]{3}{*}{25} & 5267.8 & 15 & & Y[53-98]I & 1.0 & $\mathrm{~K}[33-52] \mathrm{D}$ & 2247.7 & -0.4 & & & \\
\hline & & & & $\mathrm{N}[39-84] \mathrm{L}$ & 1.8 & & & & $\mathrm{~S}[85-129] \mathrm{L}$ & 5110.5 & 0.2 \\
\hline & & & & $\mathrm{K}[33-77] \mathrm{N}$ & -0.3 & & & & & & \\
\hline \multirow[t]{3}{*}{26} & 5143.2 & 19 & & $\mathrm{D}[48-93] \mathrm{N}$ & 0.3 & & & & & & \\
\hline & & & & $\mathrm{R}[45-89] \mathrm{T}$ & 0.3 & & & & & & \\
\hline & & & & $\mathrm{D}[52-96] \mathrm{K}$ & 0.6 & & & & & & \\
\hline $27^{d}$ & 5110.5 & 16 & 16 & $\mathrm{~S}[85-129] \mathrm{L}$ & 0.2 & $\mathrm{~K}[1-84] \mathrm{L}$ & 9676.1 & 0.5 & & & \\
\hline $28^{d}$ & 4146.3 & 15 & & $\mathrm{G}[16-52] \mathrm{D}$ & -1.0 & $\mathrm{~K}[1-15] \mathrm{H}$ & 1774.6 & -0.8 & & & \\
\hline $29^{d, e}$ & 3786.7 & 15 & & $\mathrm{G}[16-48] \mathrm{D}$ & -1.7 & $\mathrm{~K}[1-15] \mathrm{H}$ & 1774.6 & -0.8 & $\mathrm{G}[49-101] \mathrm{D}$ & 5931.3 & -0.9 \\
\hline $30^{c}$ & 3604.6 & 19 & & $\mathrm{~K}[13-43] \mathrm{T}$ & 1.3 & & & & & & \\
\hline $31^{d}$ & 3470.3 & 19 & & $\mathrm{~S}[85-115] \mathrm{C}$ & -1.5 & $\mathrm{~K}[1-84] \mathrm{L}$ & 9676.1 & 0.5 & & & \\
\hline
\end{tabular}

${ }^{a}$ Peptides generated after 10 min of incubation with MPC were separated by HPLC, and those fractions containing peptides within peak cluster 2 (Figure 2A,C) were collected and the fragments contained therein were analyzed by mass spectrometry. An additional mass spectrometry analysis was performed on the unfractionated reaction mixture to permit identification of small, complementary peptide fragments. Reactions were performed as described under Materials and Methods. Numbers indicate the position in RCM-lysozyme of the first and last amino acid in the peptide. Error refers to the difference between the observed mass and the predicted mass of the indicated peptide. ${ }^{b}$ Peptides were identified by comparing their masses to those of all of the possible random fragments of RCM-lysozyme with mass error tolerance of 500 ppm and were identified as follows: ${ }^{c}$ A single peptide matched the given molecular mass. ${ }^{d}$ An N-terminal complementary peptide was found in the mass spectrum of the total digest at the same time point. ${ }^{e} \mathrm{~A}$ C-terminal complementary peptide was found in the mass spectrum of the total digest at the same time point.

peptide in the HPLC fractions was possible (a) when only one peptide sequence with a corresponding mass was found in lysozyme or (b) when a complementary peptide having a matching $\mathrm{N}$ - or $\mathrm{C}$-terminus was found in the total digest at the same time point. Using these criteria, we were able to identify 18 of the 31 peptides observed within peak cluster 2. Masses of the fragments ranged from $3470 \mathrm{Da}$ to greater than $10000 \mathrm{Da}$, with about two-thirds of the fragments having masses greater than $7000 \mathrm{Da}$. The sizes of intermedi- ates were similar for reactions with spleen as compared to pituitary MPC. Several features of these peptides were striking. Many were formed by the removal of peptides from the N- and C-termini of RCM-lysozyme (for example, peptides 4, 9, and 10). Such peptides range from rather large intermediates of about $9 \mathrm{kDa}$ (peptides 4 and 9) to much smaller peptides ranging from 3 to $4 \mathrm{kDa}$ (peptides 28-31). A remarkable finding was the presence of a peptide corresponding to the N-terminal 84 residues of RCM-lysozyme 
A

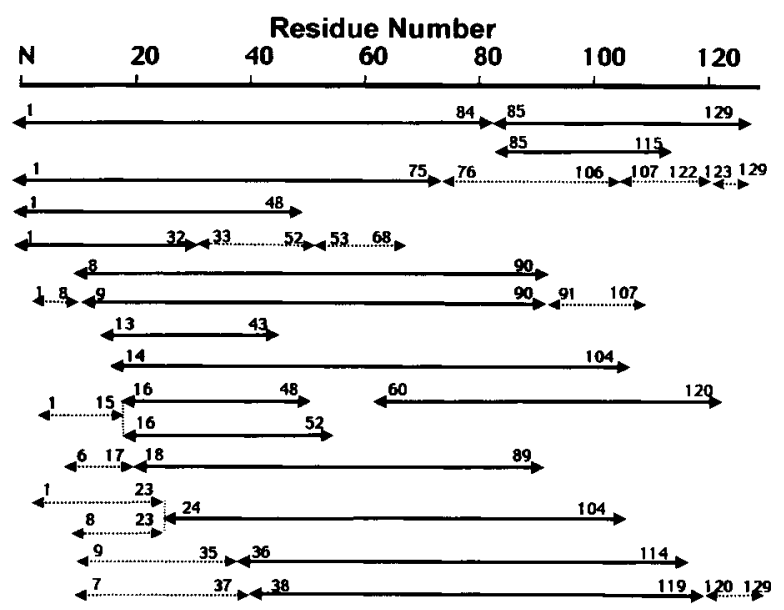

B

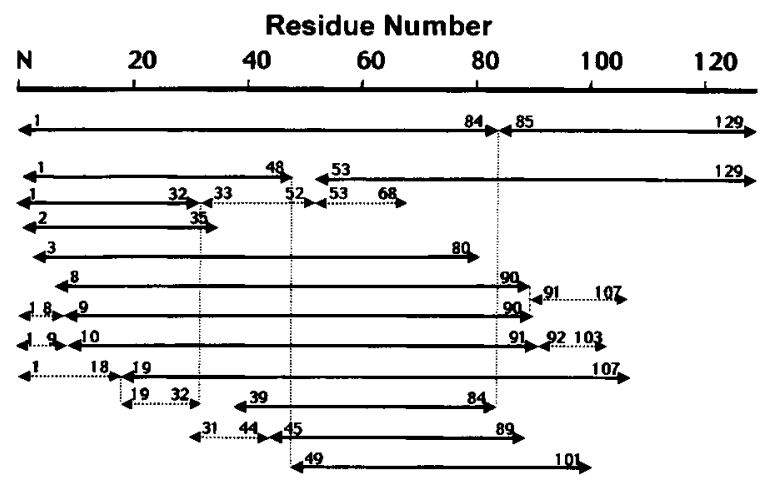

FIGURE 4: Map of intermediates of degradation and complementary peptides formed after incubation for $10 \mathrm{~min}$ of RCM-lysozyme with pituitary MPC (A) or spleen MPC (B). Isolation and identification of peptides were as described in Table 1. Solid arrows represent intermediates; dotted arrows represent complementary peptides present in the total $10 \mathrm{~min}$ incubation mixture. Numbers indicate the positions in RCM-lysozyme of the first and last amino acid residues in the peptides.

(peptide 3) and a complementary peptide having the remaining 44 residues (peptides 27), suggesting an initial cleavage between residues 84 and 85 , a location far from either the $\mathrm{N}$ - or C-terminus. To more easily appreciate the organization of initial cleavages of bonds of RCM-lysozyme, a map of the intermediate cleavage products (cluster 2) identified in reactions with pituitary MPC was constructed (Figure 4A). Many of the peptide intermediates were generated by cleavages at the $\mathrm{N}$ - and $\mathrm{C}$-termini of the protein. Several appear to have arisen by the removal of comparatively large fragments from the $\mathrm{N}$-terminus, for example the $\mathrm{K}[1-23] \mathrm{Y}$ fragment removed from the $S[24-104] \mathrm{G}$ peptide. Initial cleavages removed $\mathrm{N}$-terminal peptides of varied sizes from 9 to at least 24 amino acids. A map of large intermediates formed by the spleen enzyme revealed similar findings (Figure 4B). This organization of initial cleavages differs markedly from the highly ordered generation of small fragments predicted for processive degradation.

Intermediates Accumulate in Molar Excess Relative to $M P C$. If degradation of proteins by the MPC is processive, large peptide intermediates would be expected to remain associated with the MPC until complete degradation and release of the final fragments. In this case one would expect the molar ratios of intermediates and MPC to be close to unity. This relationship was examined by considering the relative areas of the peaks of RCM-lysozyme and of the reaction intermediates after separation by HPLC (labeled peak 2 in Figure 2A,C). Under the conditions of the reaction, approximately $50 \%$ of lysozyme has been degraded after 10 min of incubation. The combined area under the intermediate and final product peaks was similar to the decrease in area of the RCM-lysozyme peak, indicating that the majority of the products at this time point eluted within peak clusters 2 and 3. Compared to the area of the undigested lysozyme peak, the average combined areas of the intermediate peaks were $23 \%$ for spleen $(n=3$; range $7.7-41 \%)$ and $10 \%$ for pituitary $(n=2 ; 9.9-10.2 \%)$. This measurement allows one to estimate the molar ratios of the intermediates and MPC as follows. The concentration of RCM-lysozyme in the reaction was $0.17 \mathrm{mg} / \mathrm{mL}$ while that of MPC was $0.010 \mathrm{mg} /$ $\mathrm{mL}$. Assuming a molecular mass for MPC of $700 \mathrm{kDa}$ and a mass for RCM-lysozyme of $14.5 \mathrm{kDa}$, the latter was present at a molar concentration approximately 800 -fold greater than that of the MPC. Thus, the total concentration of the large intermediates is approximately 180 times that of the MPC in the reactions with spleen MPC and 80-fold greater than the concentration of MPC in incubations with pituitary MPC. Given that at most several molecules of RMC-lysozyme can pass through the pores at the entrance to the catalytic chamber of the MPC, the data indicate that the large substrate fragments dissociate from the MPC upon cleavage of RCMlysozyme. Comparison of the areas for intermediates (labeled peak 2) and end products (labeled peak 3) in Figure 2A revealed similar values, suggesting that the dissociated, high molecular weight intermediates represent on the order of $50 \%$ of all cleavage products arising from initial interactions of the MPC with RCM-lysozyme.

\section{DISCUSSION}

The analysis of peptides formed during complete degradation of RCM-lysozyme by mass spectrometry revealed a broad distribution of sizes (Figure 1), in contrast to the sharp clustering that is expected if cleavages of RCM-lysozyme by the bovine MPC were governed by a molecular ruler. Moreover, the size distribution of peptides produced by spleen MPC was comparable to that for pituitary MPC (Figure 1), indicating that the increased ability of the LMPcontaining MPC to form antigenic peptides should not be ascribed to changes in the spatial orientation of active sites to favor generation of peptides with the size of class I-restricted antigens. Whereas studies of the degradation of the insulin B-chain by the more primitive complex from archaebacteria found clustering of products around 7-8 amino acids in length (40), products generated upon complete degradation by this form of MPC of a more complex protein substrate (insulinlike growth factor) revealed no such size predilection (32), a finding similar to that in our study. We suggest, therefore, that the sizes of the final products generated by the MPC from eukaryotes are limited primarily by the ability of the MPC to hydrolyze bonds at various positions along the peptide chain or, more specifically, by the cleavage specificity of the peptidase activities of the MPC. Several lines of evidence indicate that proteolytic activities of MPC from eukaryotes express significant selectivity with respect to substrates cleaved. In earlier studies 
using naturally occurring peptides we showed that only a limited number of bonds in the peptides were cleaved and that there were marked differences in relative rates of cleavage $(30,45)$. We found that, for pituitary MPC, the nature of residues in the $\mathrm{P} 2$ and $\mathrm{P} 3$ positions have important roles in determining whether peptide aldehydes or chromogenic substrates bind to the active sites of particular MPC proteolytic activities $(30,45-47)$. Specificity studies involving the replacement with alanine of various amino acid residues in the insulin B-chain, or synthetic fragments of histone, reached a similar conclusion (48), as have studies of the sites of cleavage of proteins by the MPC $(45,49)$.

Experiments comparing pituitary and spleen MPC indicate that incorporation of the catalytically active LMP subunits markedly alters substrate specificity $(15,45)$. Studies of the MPC from interferon-treated cells reached the same conclusion $(12,16)$. Consistent with these findings, mass spectrometric analysis of fragments produced after $10 \mathrm{~min}$ of incubation showed that the spleen MPC produced several fragments not present in reactions with pituitary MPC (Table 1). Thus, our study further supports the concept that the form of MPC containing LMP subunits demonstrates altered cleavage preferences, which may be involved in the enhanced ability of the LMP-containing MPC to process certain MHC class I-restricted antigenic peptides.

The mechanism by which the MPC degrades proteins has been the topic of recent interest. Analysis of the kinetics of degradation of fluorescein isothiocyanate- (FITC-) labeled casein by the MPC from T. acidophilum (32) suggested that degradation was processive since no evidence of the accumulation of large intermediates was observed. By contrast, studies of the time course of the degradation of a synthetic ovalbumin 239-281 fragment revealed the appearance, at early times, of large intermediates of 20-40 residues in length (33). In addition, high molecular weight intermediates have been previously observed in studies of degradation of casein by chemically modified MPC (35) and after degradation of lysozyme in the presence of low concentrations of sodium dodecyl sulfate (34). Moreover, studies on the degradation of myosin heavy chain and tropomyosin by the MPC from lobster muscle showed that these proteins are also degraded to large fragments ( 66-400 kDa) (42).

We found that high molecular weight peptides appear early in the degradation of RCM-lysozyme (Figure 2) and that these fragments accumulate transiently in 80-180-fold molar excess relative to concentrations of MPC. These large fragments were further proteolyzed after longer incubation with MPC, demonstrating that they were degradation intermediates and not end products. The small size of the pores through which substrates must pass to enter the catalytic chamber $(10-20 \AA)(8,23,28,29)$ restricts the conformation and number of protein substrates entering the central canal. Hence, these findings cannot be explained by assuming that several molecules of lysozyme or its fragments are associated with each MPC particle. Thus, our findings indicate that early cleavage fragments of RCM-lysozyme dissociate from the MPC prior to complete degradation. Consistent with this interpretation, the mass spectrometric analysis of the intermediates of degradation revealed that many products arise from cleavages at both the $\mathrm{N}$ - and $\mathrm{C}$-termini of the molecule (Table 1, Figure 4) and that, in at least a few cases, initial cleavages involved bonds 40 or more amino acids removed from the N- or C-terminus. Such findings are clearly incompatible with a processive mechanism of degradation. Furthermore, our observations that during the initial stages of the degradation of RCM-lysozyme the high molecular weight products represent as much as $50 \%$ of all products formed (Figure 2A) suggest that a large proportion of initial cleavage products dissociate before undergoing further degradation.

Thus, our data indicate that degradation of proteins by the MPC involves significant dissociation and rebinding of initial cleavage products as opposed to a single binding event and a subsequent, fully processive mode of degradation. This model requires that the degradation intermediates move out of the catalytic chamber and then reenter this cavity. Movement of proteins or high molecular weight intermediates into or out of the MPC could occur either through energydependent transport process or by diffusion. Experiments show that the sequences of MPC subunits lack features of known ATPases (3) and that ATP has no appreciable effect on degradation of proteins by the MPC $(30,36-39)$, indicating that there is no energy-driven molecular mechanism for tethering protein substrates or for feeding them into the catalytic chamber. Thus, diffusion of protein substrates and degradation intermediates appears to govern the interactions of these polypeptides with the MPC. It is unclear why our findings differ from those of studies using the MPC from Thermoplasma (32), where it was found that degradation is processive.

The relative dimensions of protein substrates and the MPC suggest features that could favor dissociation of initial cleavage fragments from the MPC. Assuming that RCMlysozyme exists primarily in an extended conformation and that a single amino acid residue in a polypeptide spans approximately $3.6 \AA$, RCM-lysozyme (129 amino acids) is approximately $460 \AA$ in length. This is 3 times the length of the MPC $(150 \AA)(8,23)$. Thus, even in the case of a comparatively small protein such as RCM-lysozyme, large parts of the protein might be expected to remain outside the central canal of the MPC during the initial cleavage reactions. These extraluminal domains may greatly facilitate dissociation through diffusion following the initial cleavages and may in part explain the lack of more processive modes of degradation of this protein. An estimate of the distances through which a cleavage fragment must diffuse prior to dissociation or subsequent cleavage also provides a basis for consideration of the likelihood of further cleavage as opposed to dissociation of an intermediate. Taking the overall length of the MPC as an estimate of the length of the catalytic chamber, and assuming based on crystallography studies that the active sites are located just less than halfway along the inner surface of the catalytic chamber (overall length 150 $\AA$ ), fragments must diffuse about $60-70 \AA$ to dissociate from the MPC. By contrast, the distance a large degradation intermediate must move to position the next cleavage site adjacent to an active site is on the order of $20-80 \AA$, assuming cleavages occur at intervals of 5-20 amino acid residues, the size of the majority of the final peptide products of degradation we observed (Figure 1). This analysis suggests that the likelihood of dissociation is at least similar to that of further cleavage, a conclusion commensurate with our finding that at the $10 \mathrm{~min}$ time point, similar amounts of intermediates (labeled peak 2 in Figure 2A,C) and final 
products (labeled peak 3 in Figure 2A,C) had accumulated.

On the basis of the findings of this study, we propose a mechanism for degradation of proteins involving two parallel pathways. The model assumes that diffusion is the primary influence responsible for movement of the protein substrate or its fragments into and through the catalytic chamber of the MPC, as well as for dissociation of fragments from the MPC. Upon completion of the initial cleavage the fragment may move away from the MPC or migrate further into the catalytic chamber, resulting in an additional cleavage. Dissociated fragments could later reenter the catalytic chamber and undergo further cleavage. These steps are repeated until the protein is degraded to small fragments. Findings that intermediates are formed even during degradation of a 44-mer peptide (33) raise the possibility that degradation intermediates of smaller peptides undergo a similar series of independent cleavages separated by dissociation and later reassociation of products with the MPC. However, in some cases, all products formed during degradation of short peptides, (such as neurotensin or the oxidized B-chain of insulin) appear simultaneously (30, 31), suggesting that in some cases smaller peptides formed during the degradation of proteins may undergo substrate channeling or be trapped within the catalytic chamber until completely degraded $(30,31)$.

Our findings indicate that large polypeptide fragments are formed during the degradation of proteins by the 20S MPC and thus raise the question of the intracellular fate of these intermediates. It is suggested that small peptides formed by the MPC are degradaed by cyotosolic peptidases to component amino acids (50). Under normal circumstances, one would expect large intermediates would be rare in the cell because of the action of other proteases and helper molecules such as heat-shock proteins. However, failure of these sytems could lead to accumulation of high molecular weight intermediates. Consistent with this proposal, intermediates of degradation accumulated intracellularly in yeast with a mutation of the MPC (51). Findings of copurification of heatshock protein 90 with MPC (52) and of a role for heat-shock protein 70 in the degradation of the membrane-bound protein apolipoprotein B100 (53) raise the possibility that heat-shock proteins might function to shuttle proteins or their degradation intermediates to the MPC. The identification of KEKE motifs in the sequences of MPC subunits and certain heatshock proteins (54) suggests a structural basis for binding of heat-shock proteins to the MPC. Alternatively, the 19S cap of the $26 \mathrm{~S}$ proteasome may serve a similar function. Most cellular proteins are targeted for degradation through the covalent attachment of multiple ubiquitin molecules $(1,4$, 5 , 55). Ubiquitinylated substrates are degraded by a $26 \mathrm{~S}$ proteasome assembled from one copy of the MPC and two copies of a $19 \mathrm{~S}$ cap $(1,4,55)$. The $19 \mathrm{~S}$ cap of the $26 \mathrm{~S}$ particle contains several ATPases that may be involved in unfolding of protein substrates or guiding substrates into the catalytic chamber for degradation.

Once liberated from the catalytic chamber of the MPC, fragments of the cleaved protein become susceptible to the action of cytosolic peptidases. Of interest in this regard are recent findings implicating both MPC-dependent and MPCindependent proteolytic processing in the formation of $\mathrm{MHC}$ class I antigenic peptides (56). Thus, our findings raise the possibility that intermediates formed during degradation of proteins may be subjected to trimming by cytosolic peptidases before subsequent cleavages by the MPC. Such trimming may be relevant to antigen processing functions of the MPC.

\section{ACKNOWLEDGMENT}

We thank Dr. Marian Orlowski for many helpful discussions and for his critical review of the manuscript.

\section{REFERENCES}

1. Rechsteiner, M., Hoffman, L., and Dubiel, W. (1993) J. Biol. Chem. 268, 6065-6068.

2. Monaco, J. J., and Nandi, D. (1995) Annu. Rev. Genet. 29, 729-54.

3. Tanaka, K., and Tsurumi, C. (1997) Mol. Biol. Rep. 24, 3-11.

4. Coux, O., Tanaka, K., and Goldberg, A. L. (1996) Annu. Rev. Biochem. 65, 801-47.

5. Baumeister, W., Walz, J., Zuhl, F., and Seemuller, E. (1998) Cell 92, 367-380.

6. Harding, C. V., France, J., Song, R., Farah, J. M., Chatterjee, S., Iqbal, M., and Siman, R. (1995) J. Immunol. 155, 17671775 .

7. Rock, K. L., Gramm, C., Rothstein, L., Clark, K., Stein, R., Dick, L., Hwang, D., and Goldberg, A. L. (1994) Cell 78, $761-771$.

8. Löwe, J., Stock, D., Jap, B., Zwickl, P., Baumeister, W., and Huber, R. (1995) Science 268, 533-539.

9. Nandi, D., Jiang, H., and Monaco, J. J. (1996) J. Immunol. $156,2361-2364$

10. Hisamatsu, H., Shimbara, N., Saito, Y., Kristensen, P., Hendil, K. B., Jujiwara, T., Takahashi, E., Tanahashi, N., Tamura, T., Ichihara, A., and Tanaka, K. (1996) J. Exp. Med. 183, 18071816.

11. Monaco, J. J. (1995) J. Leukocyte Biol. 57, 543-547.

12. Gaczynska, M., Rock, K. L., and Goldberg, A. L. (1993) Nature 365, 264-267.

13. Gaczynska, M., Rock, K. L., Spies, T., and Goldberg, A. L. (1994) Proc. Natl. Acad. Sci. U.S.A. 91, 9213-9217.

14. Orlowski, M., Cardozo, C., Eleuteri, A. M., Kohanski, R. M., Kam, C. M., and Powers, J. C. (1997) Biochemistry 36, 13946-13953.

15. Eleuteri, A. M., Kohanski, R. A., Cardozo, C., and Orlowski, M. (1997) J. Biol. Chem. 272, 11824-11831.

16. Boes, B., Hengel, H., Ruppert, T., Multhaup, G., Koszinowski, U. H., and Kloetzel, P. M. (1994) J. Exp. Med. 179, 901909.

17. Fehling, H. J., Swat, W., Laplace, C., Kühn, R., Rajewsky, K., Müller, U., and von Boehmer, H. (1994) Nature 265, 1234-1237.

18. van Kaer, L. V., Ashton-Rickardt, P. G., Eichelberger, M., Gaczynska, M., Nagashima, K., Rock, K. L., Goldberg, A. L., Doherty, P. C., and Tonegawa, S. (1994) Immunity 1, $533-$ 541.

19. Cerundolo, V., Kelly, A., Elliot, T., Trowsdale, J., and Townsend, A. (1995) Eur. J. Immunol. 25, 554-562.

20. Sibille, C., Gould, K. G., Willard-Gallo, K., Thomson, S., Rivett, A. J., Powis, S., Butcher, G. W., and De Baetselier, P. (1995) Curr. Biol. 5, 923-930.

21. Tanaka, K., Yoshikura, T., Ichihara, A., Ikai, A., Nishigai, M., Morimoto, Y., Satao, M., Tanaka, N., Katsube, Y., Kameyama, K., and Takagi, T. (1988) J. Mol. Biol. 203, 985996.

22. Kopp, F., Steiner, R., Dahlmann, B., Kuehn, L., and Reinauer, H. (1986) Biochim. Biophys. Acta 872, 253-260.

23. Groll, M., Ditzel, L., Lowe, J., Stock, D., Bochtler, M., Bartunik, H. D., and Huber, R. (1997) Nature 386, 463-471.

24. Heinemeyer, W., Fischer, M., Krimmer, T., Stachon, U., and Wolf, D. H. (1997) J. Biol. Chem. 272, 25200-25209.

25. Arendt, C. S., and Hochstrasser, M. (1997) Proc. Natl. Acad. Sci. U.S.A. 94, 7156-7161.

26. Fenteany, G., Standaert, R. F., Lane, W. S., Choi, S., Corey, E. J., and Schreiber, S. L. (1995) Science 268, 726-730. 
27. Seemüller, E., Lupas, A., Stock, D., Löwe, J., Huber, R., and Baumeister, W. (1995) Science 268, 579-582.

28. Gregori, L., Hainfeld, J. F., Simon, M. N., and Goldgaber, D. (1997) J. Biol. Chem. 272, 58-62.

29. Wenzel, T., and Baumeister, W. (1995) Nat. Struct. Biol. 2, 199-203.

30. Cardozo, C., Vinitsky, A., Hidalgo, M. C., Michaud, C., and Orlowski, M. (1992) Biochemistry 31, 7373-7380.

31. Dick, L. R., Moomaw, C. R., DeMartino, G. N., and Slaughter, C. A. (1991) Biochemistry 30, 2725-2734.

32. Akopian, T. N., Kisselev, A. F., and Goldberg, A. L. (1997) J. Biol. Chem. 272, 1791-1798.

33. Niedermann, G., King, G., Butz, S., Birsner, U., Grimm, R., Shabanowitz, J., Hunt, D. F., and Eichmann, K. (1996) Proc. Natl. Acad. Sci. U.S.A. 93, 8572-8577.

34. Orlowski, M., and Michaud, C. (1989) Biochemistry 28, 92709278.

35. Yu, B., Pereira, M. E., and Wilk, S. (1991) J. Biol. Chem. 266, 17396-17400.

36. Driscoll, J., and Goldberg, A. L. (1989) Proc. Natl. Acad. Sci. U.S.A. 86, 787-791.

37. Hough, R., Pratt, G., and Rechsteiner, M. (1987) J. Biol. Chem. $262,8303-8313$.

38. McGuire, M. J., and DeMartino, G. N. (1986) Biochim. Biophys. Acta 873, 279-289.

39. Orlowski, M., Cardozo, C., and Michaud, C. (1993) Biochemistry 32, 1563-1572.

40. Wenzel, T., Eckerskorn, C., Lottspeich, F., and Baumeister, W. (1994) FEBS Lett. 349, 205-9.

41. Kisslev, A. F., Akopian, T. N., and Goldberg, A. L. (1998) J. Biol. Chem. 273, 1982-1988.

42. Mykles, D. L., and Haire, M. F. (1991) Arch. Biochem. Biophys. 288, 543-551.
43. Kohanski, R. A., and Lane, M. D. (1986) Biochem. Biophys. Res. Commun. 134, 1312-1318.

44. Beavis, R. C., and Chait, B. T. (1990) Anal. Chem. 62, 18361840.

45. Cardozo, C., and Kohanski, R. (1998) J. Biol. Chem. 273, $16764-16770$.

46. Cardozo, C., Vinitsky, A., Michaud, C., and Orlowski, M. (1994) Biochemistry 33, 6483-6489.

47. Vinitsky, A., Cardozo, C., Sepp-Lorenzino, L., Michaud, C., and Orlowski, M. (1994) J. Biol. Chem 269, 29860-29866.

48. Ehring, B., Meyer, T. H., Eckerskorn, C., Lottspeich, F., and Tampe, R. (1996) Eur. J. Biochem. 235, 404-415.

49. Nussbaum, A. K., Dick, T. P., Keilholz, W., Schirle, M., Stevanovi, C., Dietz, K., Heinemeyer, W., Groll, M., Wolf, D. H., Huber, R., Rammensee, H. G., and Schild, H. (1998) Proc. Natl. Acad. Sci. U.S.A. 95, 12504-12509.

50. Orlowski, M. (1990) Biochemistry 29, 10289-10297.

51. Mayer, T. U., Baun, T., and Jentsch, S. (1998) EMBO J. 17, 3251-3257.

52. Wagner, B. J., and Margolis, J. W. (1995) Arch. Biochem. Biophys. 323, 455-462.

53. Fisher, E. A., Zhou, M., Mitchell, D. M., Wu, X., Omura, S., Wang, H., Goldberg, A. L., and Ginsberg, H. N. (1997) J. Biol. Chem. 272, 20427-20434.

54. Realini, C., Dubeil, W., Pratt, G., Ferrell, K., and Rechsteiner, M. (1994) J. Biol. Chem. 269, 20727-20732.

55. Ciechanover, A. (1994) Cell 79, 13-21.

56. Vinitsky, A., Anton, L. D., Snyder, H. L., Orlowski, M., Bennink, J. R., and Yewdell, J. W. (1997) J. Immunol. 159, $554-564$.

BI990826H 